\title{
The Physical Products of a Splashing Water Drop
}

\author{
By C. D. Stow and R. D. Stainer* \\ Atmospheric Physics Laboratory, Department of Physics, the University of Auckland, \\ Auckland, New Zealand
}

\begin{abstract}
The physical products of splashing water drops were investigated with respect to several parameters: impact velocity, drop size, surface tension, radius of curvature and roughness of the target surface, and the depth of liquid film covering the surface of the target. It is shown that the number of droplets produced by a splash increases with surface roughness, impact velocity and drop size, but decreases with an increase in liquid film depth and with a reduction in surface tension of the drop. For a given drop size, the number of splash products is proportional to the kinetic energy of the drop at impact. The size distribution of splash products is approximately log-normal; the mean size of the ejected droplets (approx. $120 \mu \mathrm{m}$ diameter) increases with drop size, surface roughness and depth of liquid film, but decreases with increasing impact velocity and with a reduction in surface tension.

Certain empirical relationships are established which permit the number of splash products, $N$, to be estimated in terms of the conditions of impact. One such relationship gives $N=3.4 R^{3} V^{2}-63$, where $R(\mathrm{~mm})$ is the radius of a water drop impacting a flat solid surface with velocity $V\left(\mathrm{~ms}^{-1}\right)$. It is also shown that water drops of less than $0.75 \mathrm{~mm}$ in radius require an impact velocity greater than their terminal velocity if they are to eject droplets.
\end{abstract}

\section{Introduction}

Numerous studies of the event of splashing have been made and the fields of interest in which the phenomenon is of importance are quite varied. In the early phases of its investigation (Worthington: 1876, 1908) the event was a curiosity amenable to proper observation through the relatively new technique of spark photography; half a century was to pass before the event was subjected to more detailed scrutiny.

Developments in the fields of cloud physics, atmospheric electricity, soil erosion, plant diseases, and, more recently, the aerospace industry have shown that the process of splashing is often a crucial event warranting serious study. Almost without exception, recent investigations of splashing have concentrated on the observation of the hydrodynamics of the impact itself with little or no attention being paid to the final consequences of the event. Engel (1955) chemically mapped the radial flow of a splashing water drop by placing a crystal of sodium dichromate in the bottom of a drop before allowing it to fall onto

* Present affiliation: The New Zealand Meteorological Service Wellington, New Zealand. treated filter paper. She found that the water which contacted the surface first was washed to the periphery of the flow, and that water which impacted last essentially did not flow. Observations were made of initial flow patterns and their velocity, and these were correlated to impact velocity, drop size and the smoothness of the target surface. Further studies by Engel (1966, 1967), this time of splashes into deep liquids, of initial fluid flow and cavity production were reconciled with her theoretically derived expressions for such an event. The deep-water splash was also studied by Hobbs and Alkezweeny (1967). Using high-speed photography, they measured the times required for the formation of the initial crown and the subsequent Rayleigh jet. They also made a cursory study of splash products and noted that the number of products increased with impact velocity and that a velocity existed below which no products could be observed.

Hobbs and Osheroff (1967) found that the events which followed a splash depended upon the depth of the liquid layer at the target. As the depth decreased from $25 \mathrm{~mm}$ to $7 \mathrm{~mm}$ there was an increase in the height of the Rayleigh 
jet and in the number of droplets that pinched off. For depths less than $7 \mathrm{~mm}$ both effects were diminished and no drops were ejected for depths of $3 \mathrm{~mm}$ or less. These phenomena were explained by Macklin and Hobbs (1969) to be a result of the interaction between the subsurface cavity and the solid bottom of the container, the pressure gradients within the liquid being modified owing to the change in shape of the cavity as the depth of liquid decreased.

The sequence of events following the impact of a drop on a dry, solid surface has been described in detail by Levin (1970), and Levin and Hobbs (1971) have made further detailed studies of the evolution of the ensuing crown (no Rayleigh jet occurs under these conditions). The latter observed that the jets of the crown became unstable and broke up into many small fragments which were ejected at high velocities and carried for considerable distances. During the collapse of the crown, jets continued to form and break into droplets, but in this case were thrown off with small velocities and did not travel so far. They also observed that when a water drop impacted on a very smooth surface a crown was not formed and the liquid spread radially over the surface. As the impact velocity increased they found that there was an increase in the maximum diameter of the base of the crown and in the height of the crown. A corresponding decrease in the time for the crown to reach its maximum height was also noted. (For example, a drop of $3 \mathrm{~mm}$ diameter impacting at $4.8 \mathrm{~m} \mathrm{sec}^{-1}$ formed a crown $2.65 \mathrm{~mm} \mathrm{high} \mathrm{in} 0.9 \mathrm{msec}$, whilst the same size drop impacting at $1.68 \mathrm{~m} \mathrm{sec}^{-1}$ formed a crown $1.1 \mathrm{~mm}$ high in $2.3 \mathrm{msec}$.) Levin and Hobbs also made measurements of the size distribution of the droplets produced by a water drop of $3 \mathrm{~mm}$ diameter impacting at a velocity of $4.2 \mathrm{~m} \mathrm{sec}^{-1}$ on a copper hemisphere of $2.5 \mathrm{~cm}$ diameter. They noted that the distribution was lognormal with a peak between $100 \mu \mathrm{m}$ and $150 \mu \mathrm{m}$ diameter. They also examined prints of high-speed photographs and estimated that the proportion of ejected droplets that would evaporate in flight (diameter less than $50 \mu \mathrm{m}$ ) was insufficient to significantly affect the measured distribution.

Water drops splashing into layers of water of about $0.5 \mathrm{~mm}$ in depth were investigated by Levin and Hobbs (1971) and high-speed photography showed that there was very little observable difference between a splash under these conditions and a splash on a dry solid surface.
However, they noted a significant difference in the time scale of events: for a thin liquid layer the crown takes up to five times as long as collapse. They also found that the radial velocity of spread after impact was similar in the two cases, so that the presence of the liquid layer does not assist the conversion of kinetic energy of the drop into that of the forming crown. Nevertheless the wall of the crown was observed to be higher when a thin liquid layer was impacted owing to the formation of a cavity immediately after impact, the displaced material of which was incorporated into the crown wall.

During their study of the dispersal of fungus spores, Gregory, Guthrie and Bunce (1959) investigated the splashing of water drops into thin liquid layers containing a suspension of spores. They varied the depth of their water layers over the range $0.2 \mathrm{~mm}$ to $1.0 \mathrm{~mm}$ and noted that the number of splash products decreased as the depth of the layer was increased. Regardless of the conditions, a negligible proportion of ejected droplets were found at distances greater than $70 \mathrm{~cm}$ from the point of impact.

The studies described above clearly show that a number of influences are important in determining the consequences of a splashing event. The size of the drop, its velocity of impact, the roughness and curvature of the target and the extent to which the target is covered by a liquid layer have all been shown to affect the dynamics of the initial impact. However, none of these studies separately or in combination permits of a quantitative calculation of the secondary droplet population caused by a splashing event for which the governing input parameters are known; the rectification of this deficiency is the reason for the investigation described below.

\section{The experimental method}

The apparatus required was extremely simple and needs little description. However, considerable attention was given to the selection of a method of droplet detection and measurement and towards ensuring that the data was adequately sampled. Therefore preliminary experiments were performed to determine an effective arrangement of the apparatus, the range of sizes of splash products, the extent to which input conditions would affect the splashing event and the area over which products would be scattered. The variation of the free-fall velocity of various sizes of water drop with fall height was also deter- 
mined.

Large water drops were permitted to fall from stainless-steel needles of various sizes fitted to an ordinary burette onto a prepared surface a few centimetres in diameter. As a result of the impact droplets of various sizes were ejected radially from the target onto a collecting plane parallel to and a few centimetres below the target. The sizes of the majority of the splash products were found to lie in the range $50-1000$ microns, the total number, $N$, generally lay in the range 0-2000 per impact, and the maximum range from the impact point at which ejected droplets were found was of the order of $70 \mathrm{~cm}$. Angular distributions of splash products around the target accumulated from 20 splashing events showed a radial symmetry, the deviation from the mean for each angular interval of $15^{\circ}$ being $10 \%$. In the final experimental arrangement, two $20^{\circ}$ sectors placed diametrically opposite each other were used as locations of droplet detection and measurement.

Almost all the available methods of droplet detection were tried: dye-on-filter-paper, dye-inwater, dye-on-slide, oil bath, magnesium oxide layer, carbon layer, clear glass, Formvar layer, gelatine layer, coated mesh, photographic emulsion, and polyvinyl alcohol and additives. After careful consideration, the method finally adopted for the formal series of experiments conducted was the photographic emulsion technique of Koenig and Spyers-Duran (1961). The method depends upon the fact that silver halides do not react with ordinary photographic developing agents unless the silver halides have been exposed to light and the reducing agent in the developer is in an ionized form. If these conditions are fulfilled consecutively or concurrently, then the silver halides are reduced to free silver and will appear as a darkened area on the emulsion. Therefore to detect water drops, the emulsion is coated with developer and allowed to dry in complete darkness. Once the emulsion has dried it may be exposed to light for short periods without harm since only one of the two conditions necessary for the reduction of silver halides is fulfilled.

When, however, a water drop contacts the prepared surface the developer at that location becomes ionized and a dark region proportional to the size of the drop is created. A permanent record may then be obtained by treating the emulsion with an ordinary acidic fixer. The type of paper finally chosen was AGFA BH 112 paper, with a semi-matt surface, smooth texture, white tint, and grade 5 contrast. Equivalent papers made by other manufacturers would serve equally well.

A method of calibration using a carbon layer surface upon which to form droplets of various sizes was devised. It was noted that droplets resting on a carbon layer do not deform except as a result of their own hydrostatic forces. Droplets of random sizes were shaken from a hypodermic syringe onto the layer and a droplet of the required size selected. Remaining droplets were removed and the diameter of the selected droplet measured accurately under a microscope. The droplet was then deposited onto the treated emulsion surface and finally the diameter of the permanent record measured after fixing.

Droplets of diameter less than $1.0 \mathrm{~mm}$ resting on the carbon layer were observed to be undeformed. MacDonald (1954) showed that the excess pressure within such droplets due to surface tension effects is very much greater than internal hydrostatic pressures. This was confirmed by measuring droplets on a carbon layer and then dropping them into an oil bath to be remeasured.

The time between measurement of the droplet on the carbon layer and deposition on the emulsion was generally less than about five seconds; during such an interval evaporation of droplets of diameters greater than $100 \mu \mathrm{m}$ is of negligible importance.

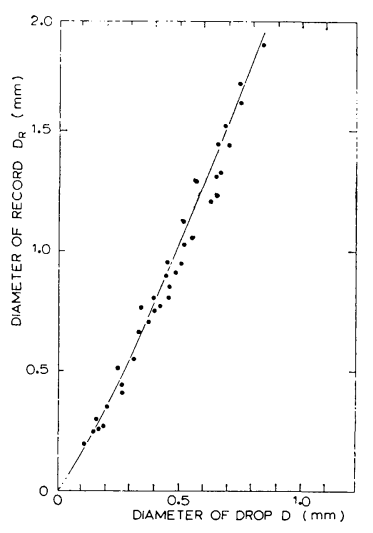

Fig. 1 The calibration curve for the photographic emulsion method of sizing and counting the ejected droplets. $D_{R}$ and $D$ are the diameters of the records formed on the emulsion and the diameters of the ejected droplets respectively. 
Figure 1 shows the calibration curve to exhibit an almost linear relationship between actual droplet diameter, $D$, and the record diameter, $D_{R}$. The best fit to these data, using a simple leastsquares technique, suggests a relationship of the form $D_{R}-2.27 D^{1.18}$, where $D$ and $D_{R}$ are measured in millimetres. Records of diameters less than 70 microns were not observed; there is expected to be a steep cut-off sensitivity in this region as the intensity of the record, being dependent on development time, will be low owing to rapid evaporation, and the size of the record is potentially small. For further details of this and other methods of droplet detection and sizing methods see Stainer and Stow (1976). It remains to describe the nature of the target and its preparation.

As pointed out by Engel (1955), the nature of the target surface is a crucial factor in determining the outcome of any splashing event. In the first instance, splashing on a plane, solid, dry surface was investigated; splashing onto curved, wetted surfaces was studied thereafter. Targets were prepared from clean metal turned on a lathe. For very rough targets, spiral grooves were cut into the surface to be impacted using a very sharp tool with a narrow edge, the degree of roughness was varied by altering the depth and pitch of the spiral. Intermediate values of roughness were obtained not but cutting grooves but by the application of carborundum. Smooth surfaces were obtained by polishing.

Wetted surfaces were obtained by applying known volumes of water to the target surface from a micro-syringe. This method is not satisfactory for the creation of thin layers of water $(<0.2 \mathrm{~mm}$ thick) on the more smooth surfaces, and it proved necessary to add a wetting agent to the layer in order to reduce the surface tension effects. For the more rough surfaces, the need for a wetting agent became less, as was pointed out by Bikerman (1970).

Curved surfaces were prepared from steel ball bearings of various sizes which were roughened using carborundum. Four values of radius of curvature were used, namely $0.4,0.65,0.8$, and $0.95 \mathrm{~cm}$.

For each target the numbers, size, and location of the secondary droplets produced by 20 successive and identical splashing events was measured from the photographic paper placed at the two detecting sites. These quantities were then analysed in terms of the following input parameters: size of the impacting drop, velocity of im- pact, curvature of target, roughness of target, thickness of the liquid layer covering the target. The results of these investigations are given below.

\section{Experimental Results}

(a) General

On almost every occasion it was evident that the splash-product diameters were distributed according to a log-normal function. This relationship has been noted by the majority of previous workers. As an example of the data obtained in the present work, Figure 2 shows normalized

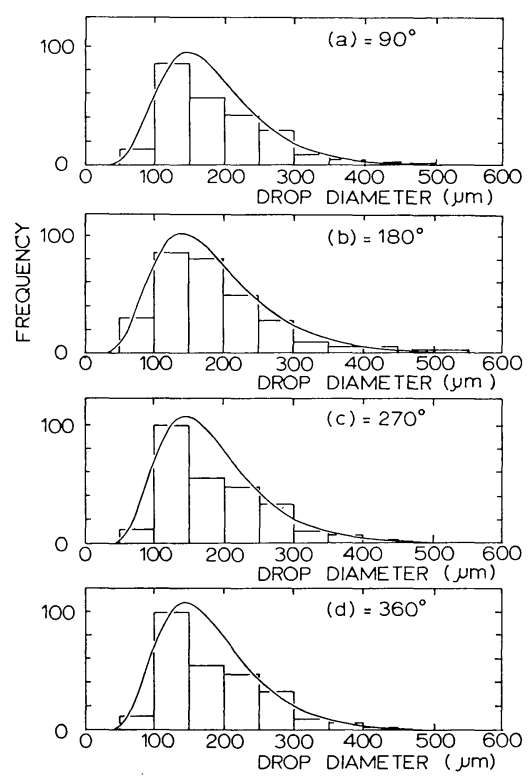

Fig. 2 Fits of the log-normal curve to the histogram data along four equally spaced radial sectors obtained from cumulative products of 20 splashing events. See also Table 1.

Table 1

\begin{tabular}{cccccccc}
\hline Position & $N$ & $\begin{array}{c}\alpha \\
(\mu \mathrm{m})\end{array}$ & $\begin{array}{c}\beta \\
(\mu \mathrm{m})\end{array}$ & $\mu$ & $\sigma$ & \multicolumn{2}{c}{$\begin{array}{c}\alpha^{\prime} \\
(\mu \mathrm{m})\end{array}\left(\begin{array}{c}\beta^{\prime} \\
(\mu \mathrm{m})\end{array}\right.$} \\
\hline $90^{\circ}$ & 250 & 188 & 77 & 5.148 & 0.395 & 186 & 76 \\
$180^{\circ}$ & 301 & 186 & 85 & 5.151 & 0.433 & 190 & 86 \\
$270^{\circ}$ & 267 & 187 & 74 & 5.135 & 0.393 & 184 & 75 \\
$360^{\circ}$ & 277 & 189 & 95 & 5.140 & 0.446 & 189 & 88 \\
\hline
\end{tabular}

histograms of the distribution of products obtained simultaneously at four locations around the target and, for each location, the fitted lognormal curve. The input conditions were a flat, slightly rough, dry target impacted by a drop of 
$4 \mathrm{~mm}$ diameter at a velocity of $3.5 \mathrm{~m} \mathrm{~s}^{-1}$. Table 1 shows the estimated total number of splash products, $N$, per event, the experimental mean diameter, $\alpha$, and the experimental standard deviation, $\beta$, together with the fitted parameters $\mu$ and $\alpha$ for the log-normal distribution

$$
L(d)=\frac{1}{d \sigma \sqrt{2 \pi}} \exp \left[-\frac{1}{2 \sigma^{2}}(\ln d-\mu)^{2}\right](1)
$$

where $\mu$ and $\sigma$ are the mean and variance of the logarithm of the distributed droplet diameters, $d$, respectively. As shown by Aitchison and Brown (1957) the distribution of Equation (1) has a mean $\alpha^{\prime}$ and a variance $\beta^{\prime 2}$ given by:

$$
\begin{aligned}
\alpha^{\prime} & =\exp \left(\mu+(1 / 2) \sigma^{2}\right) \\
{\beta^{\prime}}^{2} & =\alpha^{\prime 2}\left(e^{\sigma^{2}}-1\right)
\end{aligned}
$$

The parameters $\mu$ and $\sigma^{2}$ of the log-normal distribution may be estimated by graphical methods using, for example, log-probability plotting. Aitchison and Brown (1957) regard such methods as unreliable and have promoted analytical or numerical methods of estimation. In the present work, these parameters were calculated using Marquardt's algorithm. Table 1 also shows the calculated values of $\alpha^{\prime}$ and $\beta^{\prime}$. It may be seen from the data that the log-normal distribution function is adequate to describe the results insofar as there is excellent correspondence between the quantities $\alpha$ and $\alpha^{\prime}$, and $\beta$ and $\beta^{\prime}$. The quantity $\sigma$ of the fitted distributions shows some variation from one sample to another, though this fact does not carry great weight as a reason for rejecting the log-normal model. The mean, $\mu$, remains sensibly constant.

In the detailed results described below, experimental distributions are shown in terms of the equivalent smoothed log-normal curve for ease of comparison. Where a significant departure from such a distribution occurs, data are shown in histogram form. On no occasion was there evidence to justify the fitting of other than a log-normal function to the data.

(b) The effect of the variation of the surface roughness of the target.

For very smooth surfaces, splashing produces few secondary droplets. Consequently, for the series of experiments performed here, the smoothest surface which produced a measurable quantity of products was that obtained by acting upon a flat mild steel surface with grade 240 carborundum. A medium-rough target surface was obtained by cutting in it a spiral of $0.005 \mathrm{~cm}$ depth and $0.15 \mathrm{~mm}$ pitch, and a very rough sur-
Table 2

\begin{tabular}{lrrrrr} 
Surface & $N$ & $\mu$ & $\sigma$ & $\begin{array}{c}\alpha^{\prime} \\
(\mu \mathrm{m})\end{array}$ & $\begin{array}{c}\beta^{\prime} \\
(\mu \mathrm{m})\end{array}$ \\
\hline Smooth & 7 & - & - & 618 & 294 \\
Medium & 552 & 5.098 & 0.424 & 179 & 79 \\
Rough & 793 & 5.430 & 0.548 & 265 & 157 \\
\hline
\end{tabular}

face obtained by cutting a spiral of $0.01 \mathrm{~cm}$ depth and $0.35 \mathrm{~mm}$ pitch. Table 2 gives the values of $N, \mu, \sigma, \alpha^{\prime}$ and $\beta^{\prime}$ for each target when it was impacted by a water drop of $2.0 \mathrm{~mm}$ radius at a velocity of $4.6 \mathrm{~m} \mathrm{~s}^{-1}$. It is evident that as the roughness of the target surface is increased more droplets were produced. The smooth surface produced few fragments, of which the greater proportion exceeded 400 microns in diameter, and of which no fit to a log-normal distribution was possible; the actual distribution is shown in Figure 3 . The medium and rough targets, on the other hand, caused $N$ to increase by two orders of magnitude and produced secondary droplets whose distribution of sizes was lognormal, as shown in Figure 4. Also, for the smooth surface no droplets were detected further

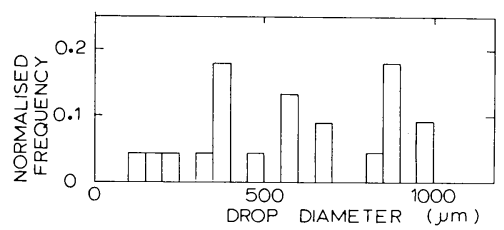

Fig. 3 The distribution of the sizes of ejecta from an impact with a smooth, dry target surface. These data were derived from 40 splashing events where a drop of $2 \mathrm{~mm}$ radius impacted at $4.0 \mathrm{~m}$ $\mathrm{s}^{-1}$.

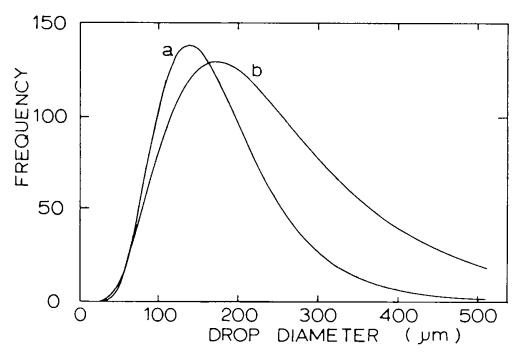

Fig. 4 Showing the effect of change of surface roughness of a dry target. The impact conditions are the same as for Figure 3. Curve (a) was obtained using the medium target, and Curve (b) using using the rough target. 
than $14 \mathrm{~cm}$ from the point of impact, whilst for the other surfaces droplets were found up to $70 \mathrm{~cm}$ distant. From Figure 4 it may be seen that for the more rough surface the mode moved to a greater value and at the same time the numbers of droplets in the range of diameter 70-180 microns was depleted; simultaneously, the numbers of droplets of diameter in excess of 180 microns increased appreciably.

(c) The effect of the variation of impact velocity

For this experiment, water drops of $2.0 \mathrm{~mm}$ radius were caused to impact the target of medium roughness at velocities in the range 2.0 to $8.4 \mathrm{~m} \mathrm{~s}^{-1}$, that is, at up to $95 \%$ of the terminal velocity. The results are summarized numerically in Table 3 and graphically in Figure 5. It is

Table 3

\begin{tabular}{crcccc}
\hline $\begin{array}{c}V \\
\left(\mathrm{~ms}^{-1}\right)\end{array}$ & $N$ & $\mu$ & $\sigma$ & $\begin{array}{c}\alpha^{\prime} \\
(\mu \mathrm{m})\end{array}$ & $\begin{array}{c}\beta^{\prime} \\
(\mu \mathrm{m})\end{array}$ \\
\hline 2.0 & 27 & 5.226 & 0.307 & 195 & 61 \\
2.8 & 147 & 5.193 & 0.337 & 191 & 70 \\
3.5 & 267 & 5.141 & 0.411 & 186 & 80 \\
4.0 & 332 & 5.136 & 0.516 & 195 & 108 \\
4.6 & 552 & 5.098 & 0.424 & 179 & 79 \\
5.8 & 768 & 5.037 & 0.436 & 169 & 77 \\
7.2 & 1298 & 4.936 & 0.408 & 151 & 64 \\
8.4 & 1999 & 4.953 & 0.457 & 177 & 86 \\
\hline
\end{tabular}

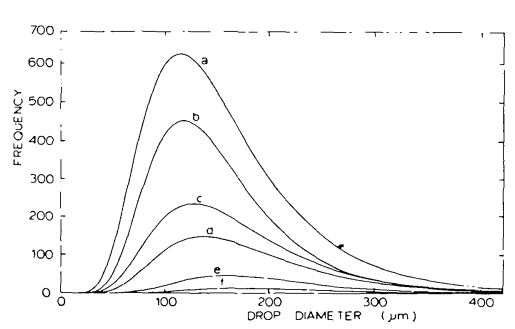

Fig. 5 The log-normal distributions of splash products formed when a drop of radius $2 \mathrm{~mm}$ collides with a dry target of medium roughness at various impact velocities:
(a) $8.4 \mathrm{~m} \mathrm{~s}^{-1}$;
(c) $5.8 \mathrm{~m} \mathrm{~s}^{-1}$;
(e) $2.8 \mathrm{~m} \mathrm{~s}^{-1}$;
(b) $7.2 \mathrm{~m} \mathrm{~s}^{-1}$;
(d) $4.6 \mathrm{~m} \mathrm{~s}^{-1}$;
(f) $2.0 \mathrm{~m} \mathrm{~s}^{-1}$.

apparent that an increase in impact velocity by a factor of two produces better than an order of magnitude increase in the quantity $N$. The best straight-line fit to these data gives

$$
N=26 V^{2}-63
$$

where $V$ is measured in metres per second. The

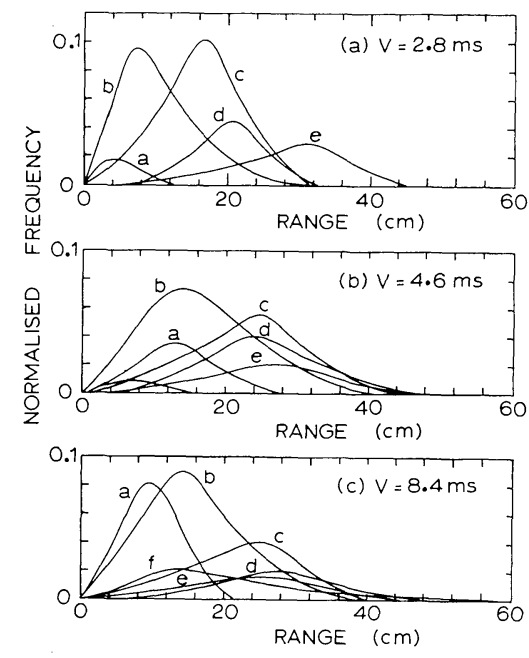

Fig. 6 Normalized curves showing the radial distribution of various size groups of ejecta: (UPPER CURVES): impact velocity, $V$, is $2.8 \mathrm{~m} \mathrm{~s}^{-1}$ and (a) $\mathrm{d}<$ $100 \mu \mathrm{m}$; (b) $100<\mathrm{d}<150 \mu \mathrm{m}$; (c) $150<\mathrm{d}<$ $200 \mu \mathrm{m} ; \quad$ (d) $200<\mathrm{d}<250 \mu \mathrm{m} ; \quad$ (e) $\mathrm{d}<$ $250 \mu \mathrm{m}$. (CENTRE CURVES): impact velocity is $4.6 \mathrm{~ms}^{-1}$ and (a) $\mathrm{d}<100 \mu \mathrm{m}$; (b) $100<\mathrm{d}<150 \mu \mathrm{m} ;$ (c) $150<\mathrm{d}<200 \mu \mathrm{m}$; (d) $200<\mathrm{d}<250 \mu \mathrm{m}$; (e) $250<\mathrm{d}<300 \mu \mathrm{m}$ (LoWER CURVES): impact velocity is $8.4 \mathrm{~m} \mathrm{~s}^{-1}$, and (a)-(f) as for centre curves.

correlation coefficient of 0.99 indicates an extremely close fit.

In terms of increasing impact velocity, it may be seen from Table 3 that the quantities $\mu$ and $\sigma$ decrease and increase in value respectively. Figure 6 shows the radial number-distribution of the different size components of the splash products for three values of $V$. It may be noted that the droplets found closest to the target approximately satisfy the condition $150 \mu \mathrm{m}>d>300 \mu \mathrm{m}$.

(d) The effect of the variation of the size of the impacting water drop

Data were obtained using the medium-rough target and an impact velocity of $4 \mathrm{~m} \mathrm{~s}^{-1}$ for drops of radius $1.1 \mathrm{~mm}, 1.5 \mathrm{~mm}$, and $2.0 \mathrm{~mm}$.

Table 4 and Figure 7 summarize the situation.

Table 4

\begin{tabular}{|c|c|c|c|c|c|}
\hline $\begin{array}{c}\text { Drop } \\
\text { Radius } \\
(\mathrm{mm})\end{array}$ & $\begin{array}{c}\text { Kinetic } \\
\text { Energy } \\
\text { (ergs) }\end{array}$ & $N$ & $\mu$ & $\sigma$ & $\begin{array}{c}\alpha^{\prime} \\
(\mu \mathrm{m})(\mu \mathrm{m})\end{array}$ \\
\hline 1.1 & 446 & 68 & 5.036 & 0.326 & $162 \quad 54$ \\
\hline 1.5 & 1130 & 136 & 5.110 & 0.393 & $178 \quad 73$ \\
\hline 2.0 & 2681 & 332 & 5.136 & 0.516 & $195 \quad 108$ \\
\hline
\end{tabular}




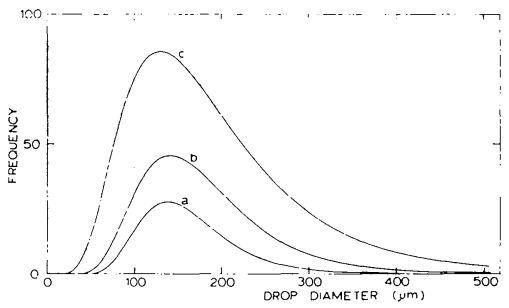

Fig. 7 The size distribution of products formed by the impaction of different sizes of drop with the medium target at an impact velocity of $4.0 \mathrm{~m} \mathrm{~s}^{-1}$ : (a) drop radius $=1.1 \mathrm{~mm}$; $(\mathrm{b})=1.5 \mathrm{~mm}$; (c) $=2.0 \mathrm{~mm}$.
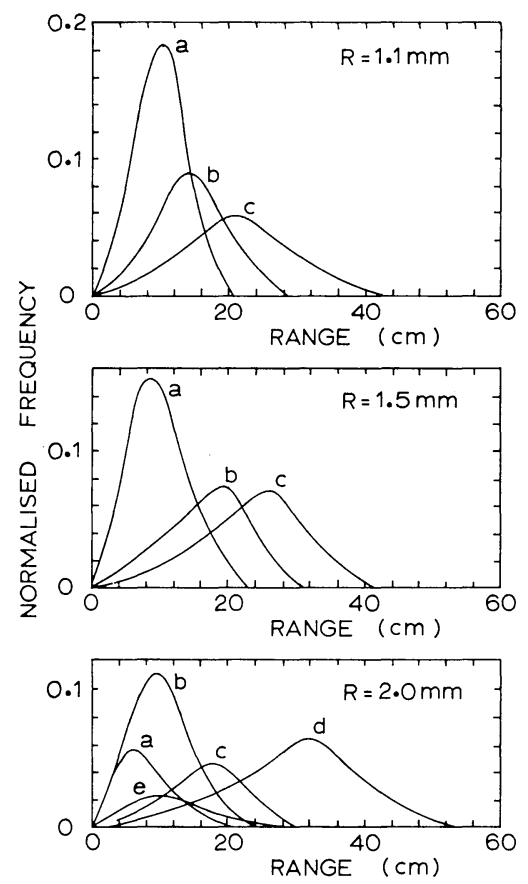

Fig. 8 The radial distribution of ejecta of different sizes. (UPPER CURVES): drop radius, $R$, is $1.1 \mathrm{~mm}$, and (a) $\mathrm{d}<$ $150 \mu \mathrm{m} ; \quad$ (b) $150<\mathrm{d}<200 \mu \mathrm{m}$; (c) $200<$ $\mathrm{d}<400 \mu \mathrm{m}$. CENTRE CURVES: (a) $\mathrm{d}<$ $150 \mu \mathrm{m}$; (b) $150<\mathrm{d}<200 \mu \mathrm{m}$; (c) $200<\mathrm{d}<$ $600 \mu \mathrm{m}$. LOWER CURVES: (a) $\mathrm{d}<$ $100 \mu \mathrm{m}$; (b) $100<\mathrm{d}<150 \mu \mathrm{m}$; (c) $150<\mathrm{d}$ $<200 \mu \mathrm{m}$; (d) $200<\mathrm{d}<400 \mu \mathrm{m}$; (e) $400<$ $\mathrm{d}<700 \mu \mathrm{m}$.

As the drop radius, $R$, is increased, there is an increase in the values of $N, \mu$, and $\sigma$. Figure 8 shows the radial location of the droplet products.

(e) The effect of variation of the surface tension of the liquid

Contamination (using detergent) of the water
Table 5

\begin{tabular}{cccccc}
\hline $\begin{array}{c}\gamma \\
\left(N \mathrm{~m}^{-1}\right)\end{array}$ & $N$ & $\mu$ & $\alpha$ & $\begin{array}{c}\alpha^{\prime} \\
(\mu \mathrm{m})\end{array}$ & $\begin{array}{c}\beta^{\prime} \\
(\mu \mathrm{m})\end{array}$ \\
\hline 0.035 & 444 & 4.831 & 0.417 & 137 & 60 \\
0.057 & 465 & 4.844 & 0.430 & 140 & 63 \\
0.073 & 552 & 5.098 & 0.424 & 179 & 79 \\
\hline
\end{tabular}

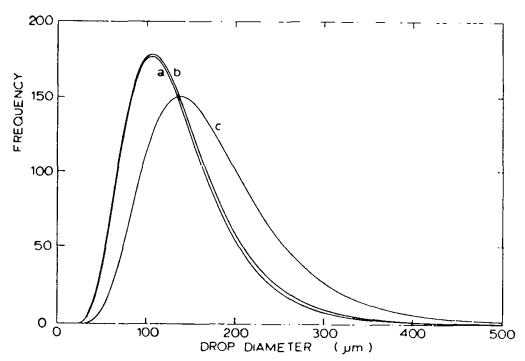

Fig. 9 The size distribution of products formed by the impaction of a drop of radius $2 \mathrm{~mm}$ at an impact velocity of $4.6 \mathrm{~m} \mathrm{~s}^{-1}$ with a medium-rough target: (a) surface tension of drop, $\gamma=0.035 \mathrm{~N}$ $\mathrm{m}^{-1}$; (b) $\gamma=0.052 \mathrm{~N} \mathrm{~m}^{-1}$; (c) $\gamma=$ $0.073 \mathrm{~N} \mathrm{~m}^{-1}$.

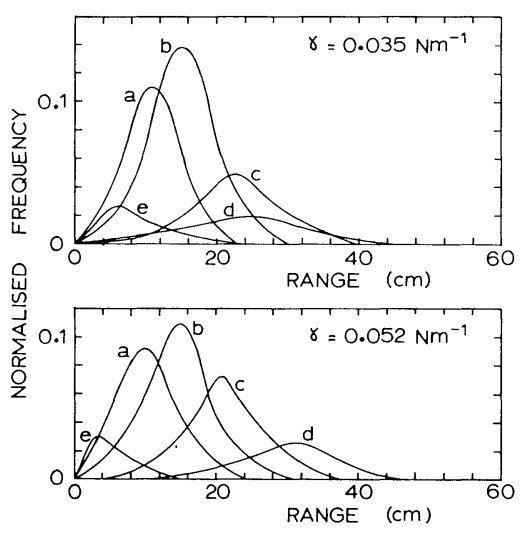

Fig. 10 Normalized curves showing the radial distribution of various size groups of ejecta. UPPER CURVES: surface tension, $\gamma=0.035 \mathrm{~N} \mathrm{~m}^{-1}$, and (a) $\mathrm{d}<$ $100 \mu \mathrm{m}$; (b) $100<\mathrm{d}<150 \mu \mathrm{m}$; (c) $150<\mathrm{d}<200 \mu \mathrm{m} ; \quad$ (d) $200<\mathrm{d}<400 \mu \mathrm{m}$; (e) $\mathrm{d}>400 \mu \mathrm{m}$. LOWER CURVES: as for upper curves, except that $\gamma=$ $0.052 \mathrm{~N} \mathrm{~m}^{-1}$. These data were obtained when a drop of radius $2 \mathrm{~mm}$ impacted with a medium-rough target at $4.6 \mathrm{~m} \mathrm{~s}^{-1}$. The curves for $\gamma=$ $0.073 \mathrm{~N} \mathrm{~m}^{-1}$ are given in Figure 6 (centre).

comprising the impacting drop enabled the surface tension, $\gamma$, of the water to be varied over 
the range $0.035-0.073 \mathrm{Nm}^{-1}$. Using the mediumrough target, a drop size of $2 \mathrm{~mm}$ radius, and an impact velocity of $4.6 \mathrm{~m} \mathrm{~s}^{-1}$ provided the details shown in Table 5, Figure 9 and Figure 10. The number of droplets produced decreases only moderately with decreasing $\gamma$. On the other hand, there is a pronounced shift of the mode from 140 microns to 100 microns diameter with little change in the value of $\gamma$. There is therefore an increase in the number of small droplets and a corresponding decrease in the numbers of the larger droplets when $\gamma$ is reduced.

(f) The corresponding effects associated with the impact of drops with surfaces covered by thin liquid films

In these experiments, thin films of water were applied to plane targets of different degrees of roughness. After each impact with a $2 \mathrm{~mm}$ radius

Table 6

\begin{tabular}{cccccc}
\hline $\begin{array}{c}t \\
(\mathrm{~mm})\end{array}$ & $N$ & $\mu$ & $\sigma$ & $\begin{array}{c}\alpha^{\prime} \\
(\mu \mathrm{m})\end{array}$ & $\begin{array}{c}\beta^{\prime} \\
(\mu \mathrm{m})\end{array}$ \\
\hline 0.03 & 205 & 4.882 & 0.336 & 140 & 48 \\
0.06 & 656 & 5.121 & 0.408 & 182 & 77 \\
0.11 & 615 & 5.346 & 0.699 & 268 & 213 \\
0.22 & 465 & 5.267 & 0.658 & 241 & 177 \\
0.45 & 384 & 5.303 & 0.596 & 240 & 157 \\
\hline
\end{tabular}

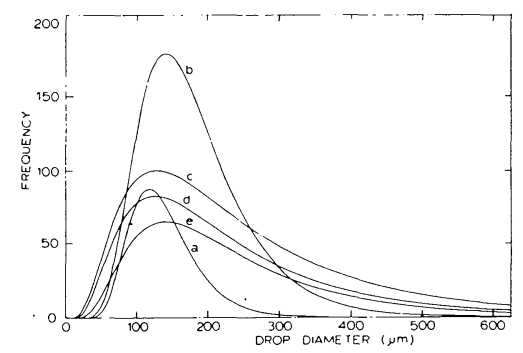

Fig. 11 The log-normal distributions of product size obtained when a drop of radius $2 \mathrm{~mm}$ impacts at a velocity of $4.0 \mathrm{~m} \mathrm{~s}^{-1}$ with a medium-rough target whose surface is covered with varying depths of liquid: (a) liquid depth, $t=$ $0.03 \mathrm{~mm}$; (b) $t=0.06 \mathrm{~mm}$; (c) $t=0.11$ $\mathrm{mm}$; (d) $t=0.22 \mathrm{~mm}$; (e) $t=0.45 \mathrm{~mm}$.

drop at $4 \mathrm{~m} \mathrm{~s}^{-1}$ the liquid film was removed and replaced. Five different layer thickness were used, namely $0.03 \mathrm{~mm}, 0.06 \mathrm{~mm}, 0.11 \mathrm{~mm}, 0.22 \mathrm{~mm}$, and $0.45 \mathrm{~mm}$. Table 6 shows the data obtained for the medium-rough surface under these conditions, and Figure 11 shows the corresponding log-normal fit to these data.

As before, the range distributions for various
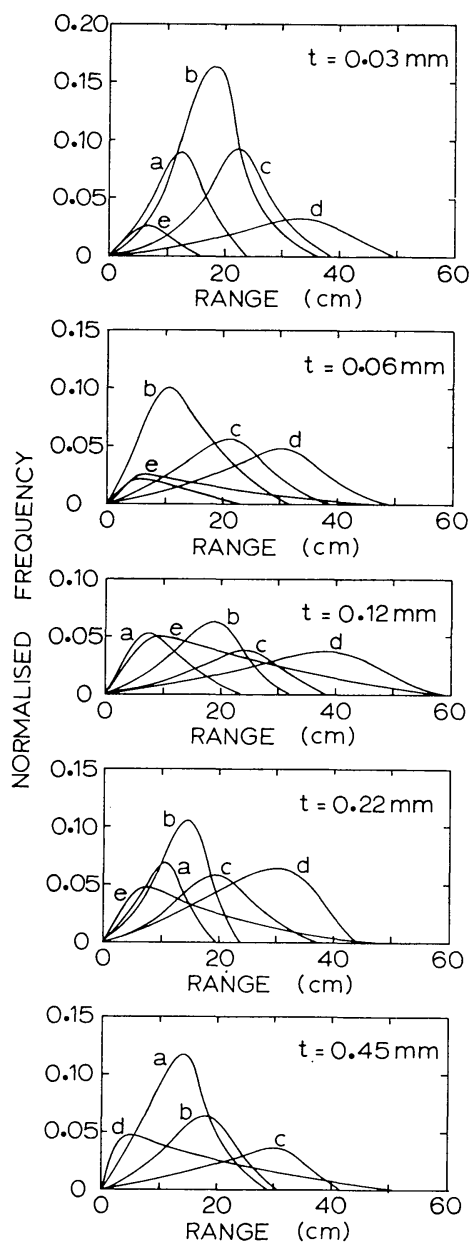

Fig. 12 The radial distribution of various size groups of ejecta formed under the impact conditions of Figure 11. Except where the film thickness, $t$, is $0.45 \mathrm{~mm}$, the curves correspond to: (a) $\mathrm{d}<100 \mu \mathrm{m}$; (b) $100<\mathrm{d}<150 \mu \mathrm{m}$; (c) $150<$ d $<200 \mu \mathrm{m} ; \quad$ (d) $200<\mathrm{d}<400 \mu \mathrm{m}$; (e) $\mathrm{d}>400 \mu \mathrm{m}$. For $t=0.45 \mathrm{~mm}$ : (a) $\mathrm{d}<$ $150 \mu \mathrm{m}$; (b) $150<\mathrm{d}<200 \mu \mathrm{m}$; (c) $200<$ $\mathrm{d}<400 \mu \mathrm{m}$; (d) d $>400 \mu \mathrm{m}$.

Table 7

\begin{tabular}{cccccc}
\hline $\begin{array}{c}t \\
(\mathrm{~mm})\end{array}$ & $N$ & $\mu$ & $\sigma$ & $\begin{array}{c}\alpha^{\prime} \\
(\mu \mathrm{m})\end{array}$ & $\begin{array}{c}\beta^{\prime} \\
(\mu \mathrm{m})\end{array}$ \\
\hline 0.03 & 385 & 5.091 & 0.459 & 190 & 115 \\
0.06 & 538 & 5.274 & 0.432 & 225 & 128 \\
0.11 & 465 & 5.234 & 0.466 & 209 & 102 \\
0.22 & 372 & 5.619 & 0.609 & 331 & 222 \\
0.45 & 300 & 5.282 & 0.599 & 235 & 154 \\
\hline
\end{tabular}

sizes of products are shown in Figure 12. Table 7 and Figure 13 show the results for the very rough target surface. 


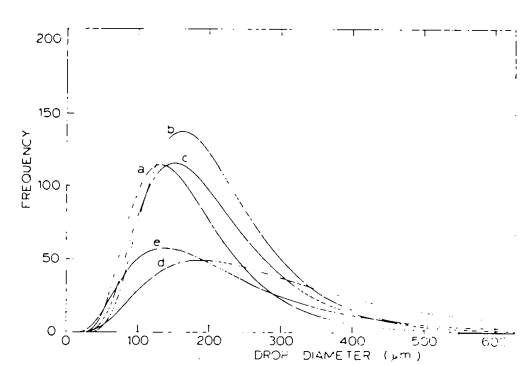

Fig. 13 As for Figure 11 except that the liquid layers now cover a rough target surface.

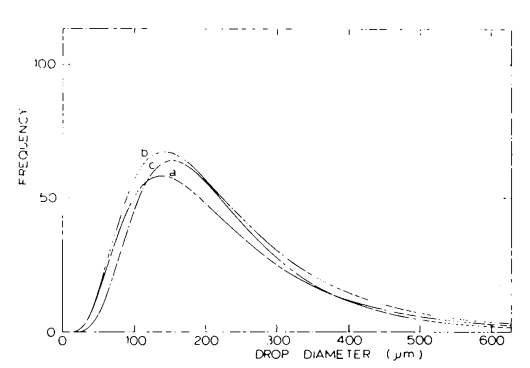

Fig. 14 Showing the effect on the size distribution of splash products when the roughness of the target surface is varied beneath a liquid layer of thickness $0.45 \mathrm{~mm}$ : (a) smooth; (b) mediumrough; (c) rough. The impacting drop is of radius $2 \mathrm{~mm}$ and has a velocity relative to the target of $4.0 \mathrm{~m} \mathrm{~s}^{-1}$.

Table 8

\begin{tabular}{cccccc}
\hline $\begin{array}{c}t \\
(\mathrm{~mm})\end{array}$ & $N$ & $\mu$ & $\sigma$ & $\begin{array}{c}\alpha^{\prime} \\
(\mu \mathrm{m})\end{array}$ & $\begin{array}{c}\beta^{\prime} \\
(\mu \mathrm{m})\end{array}$ \\
\hline 0.45 & 351 & 5.298 & 0.517 & 229 & 127 \\
\hline
\end{tabular}

Only one layer thickness of $0.45 \mathrm{~mm}$ was possible on the smooth target owing to surface tension effects; Figure 14 compares the overall size distributions of the products from the three targets for a liquid-layer thickness of $0.45 \mathrm{~mm}$. The numerical data for the smooth target are given in Table 8 .

(g) The effect of variation of curvature of the target surface

Four different values of radius of curvature of Table 9

\begin{tabular}{cccccc}
\hline $\begin{array}{c}C \\
(\mathrm{~cm})\end{array}$ & $N$ & $\mu$ & $\sigma$ & $\begin{array}{c}\alpha^{\prime} \\
(\mu \mathrm{m})\end{array}$ & $\begin{array}{c}\beta^{\prime} \\
(\mu \mathrm{m})\end{array}$ \\
\hline 0.95 & 260 & 4.785 & 0.419 & 130 & 57 \\
0.80 & 305 & 4.905 & 0.480 & 151 & 77 \\
0.65 & 260 & 4.958 & 0.421 & 155 & 68 \\
0.40 & 227 & 5.057 & 0.407 & 170 & 72 \\
\hline
\end{tabular}

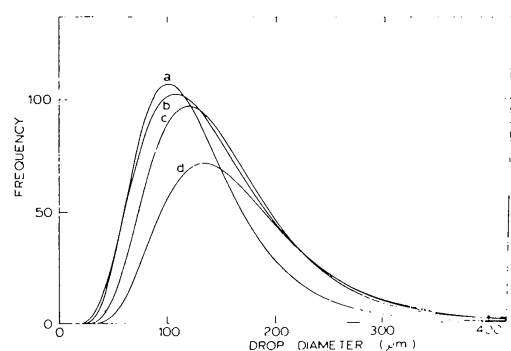

Fig. 15 Log-normal size distributions of the numbers of ejecta obtained when a drop of $2 \mathrm{~mm}$ radius impacts at a velocity of $4.0 \mathrm{~m} \mathrm{~s}^{-1}$ with a dry, medium-rough target of varying radius of curvature: (a) radius of curvature, $C=0.95 \mathrm{~cm}$; (b) $C=0.8 \mathrm{~cm}$; (c) $C=$ $0.65 \mathrm{~cm}$; (d) $C=0.4 \mathrm{~cm}$.
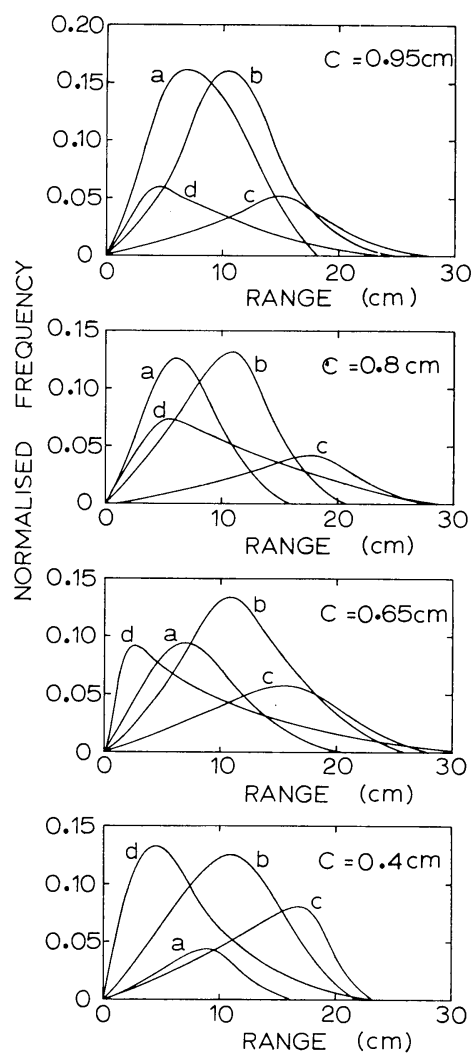

Fig. 16 Showing the radial distribution of droplet products of various size groups under the conditions of Figure 15. For all curves: (a) $\mathrm{d}<100 \mu \mathrm{m}$; (b) $100<\mathrm{d}<150 \mu \mathrm{m} ; \quad$ (c) $150<\mathrm{d}<200 \mu \mathrm{m}$; (d) $\mathrm{d}>200 \mu \mathrm{m}$.

the target, $C$, were used: $0.40 \mathrm{~cm}, 0.65 \mathrm{~cm}$, $0.80 \mathrm{~cm}$, and $0.95 \mathrm{~cm}$. Table 9 shows the data 
Table 10

\begin{tabular}{cccccc}
\hline $\begin{array}{c}C \\
(\mathrm{~cm})\end{array}$ & $N$ & $\mu$ & $\sigma$ & $\begin{array}{c}\alpha^{\prime} \\
(\mu \mathrm{m})\end{array}$ & $\begin{array}{c}\beta^{\prime} \\
(\mu \mathrm{m})\end{array}$ \\
\hline 0.95 & 56 & 4.818 & 0.248 & 128 & 32 \\
0.80 & 72 & 4.913 & 0.386 & 147 & 59 \\
0.65 & 44 & 5.051 & 0.391 & 169 & 69 \\
0.40 & 44 & 5.110 & 0.264 & 189 & 51 \\
\hline
\end{tabular}

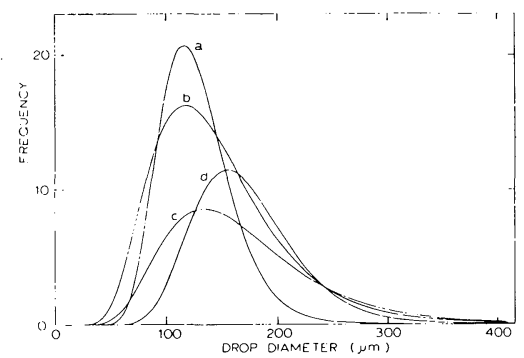

Fig. 17 As for Figure 5, but here the impacting drop is of radius $1.1 \mathrm{~mm}$. The impact velocity is still $4.0 \mathrm{~m} \mathrm{~s}^{-1}$.

obtained when drops of $2 \mathrm{~mm}$ radius impact at $4.0 \mathrm{~m} \mathrm{~s}^{-1}$ with the dry surface of each target. The usual graphical data is shown in Figures 15 and 16.

For comparison, a further experimental set of data was obtained when the impact was with a drop of $1.1 \mathrm{~mm}$ radius at the same impact velocity; these results are given in Table 10 and Figure 17.

It may be seen that the quantity $N$ was more or less independent of $C$, but that for increasing curvature the mode moved to a larger value of radius of the secondary droplets. For curved target surfaces, products were not ejected to such great distances as for plane target surfaces. As before, the largest products were found close to the point of impact.

\section{Discussion of the Results}

Firstly, it should be noted that there are marked differences between the splashing of water drops on dry, solid surfaces and splashing into deep liquid. The splash of a water drop on a solid surface is a much more rapid event than the other. Also, no Rayleigh jet is formed during a liquid-solid impact. However, in both cases jets are formed on the crown itself and these may disrupt to produce secondary droplets. According to Levin (1970), the condition for such a breakup is that

$$
\lambda>2 \pi a
$$

where $\lambda$ is the wavelength of the instability and $a$ is the jet radius. Thus the thicker the jet the larger are the ejected droplets. The number and size of the jets formed on the rim of the crown is determined by the nature of the wave disturbance set up within the fluid after impact. It is to be expected, therefore, that liquid-film thickness and target surface structure would be factors in determining product characteristics through their control of resonances in the dispersing liquid. These and other effects are discussed below in terms of the sequence of results presented above.

\section{(a) The influence of surface roughness}

During the radial flow of liquid immediately after impact, undulations in the target surface will exert an orographic influence upon the flow which will favour perturbations of wavelength of the same order of magnitude as the dimensions of the undulations. The perturbations so produced will be incoherent and their amplitude may be expected to increase with increasing roughness. On such a basis, the rougher the target surface, the greater will be the amplitude and wavelength of the resonances in the crown which are set up before the entire splashing event is over. Owing to the loose nature of the coupling between roughness and crown geometry in practice, this particular effect should be regarded as a secondary one. Nevertheless the effect serves to predict correctly an increase in splash product size with an increase in surface roughness.

Probably of greater importance is the control of frictional forces during radial flow by the variation of surface roughness. According to Levin and Hobbs (1971), the formation of the circular wall which subsequently develops into a crown is to be attributed to surface tension forces acting immediately after impact and before the impacting drop is completely deformed. These forces, according to Levin and Hobbs, act upwards and outwards from the initial point of contact. However, for precipitation-sized water drops (of radius greater than $0.5 \mathrm{~mm}$ ) impacting at velocities close to their terminal velocities in air, the kinetic energy of translation is far greater than the surface free energy and can be expected to dominate in the early stages of the splashing event. In such circumstances the effect of friction on radial flow cannot be neglected.

The dissipation of energy through frictional contact with the target surface should substantially reduce the energy available for the formation 
of the circular wall and crown and also markedly reduce the fluid velocities close to the target surface. This effect, however, will be offset to some degree since, as mentioned by Levin, and Levin and Hobbs, frictional forces obviously play a role in initiating the wall and crown; this fact is demonstrated by the experience that very smooth target surfaces inhibited the production of secondary droplets, as shown in Figure 4.

\section{(b) The influence of impact velocity}

A linear relationship was found to exist between the total number of droplets, $N$, resulting from a single splash and the square of the impact velocity, $V$. The empirical relationship was found to be of the form of Equation (3), that is,

$$
N=26 V^{2}-63 \text {. }
$$

If the number of secondary droplets is, in fact, a linear function of the kinetic energy of the impacting drop, then

$$
N=K\left((1 / 2) m V^{2}\right)+C
$$

where $m$, the mass of the drop concerned is $4 / 3 \pi R^{3} \rho$, $\rho$ being the density of the liquid forming the drop. Thus Equation (5) becomes:

$$
N=K\left((2 / 3) \pi R^{3} \rho V^{2}\right)+C
$$

or, for water drops,

$$
N=K \cdot 2100 R^{3} V^{2}+C
$$

where $R$ is in $\mathrm{mm}$ and $V$ in $\mathrm{m} \mathrm{s}^{-1}$. Using the data of Table 3, Equation (7) becomes

$$
N=3.4 \times R^{3} V^{2}-63
$$

for a dry target of medium roughness. Within reasonable limits, such an equation may be expected to apply for velocities of impact greater than the terminal velocity of the particular drop in question. In general, the constants $K$ and $C$ of Equations (5)-(7) are dependent on the other parameters controlling the input conditions.

With increasing impact velocity, Levin and Hobbs (1971) found that the maximum diameter of the base of the wall and the height of the wall increases. Thus, for an impacting drop of a given size, the wall may be expected to become thinner at the same time. Consequently, the crown jets will be smaller in diameter, and smaller and more numerous droplets should be ejected. However, Table 3 shows that the quantity $\mu$ decreased in an essentially monotonic fashion as $V$ was increased for a fixed size of impacting drop. Figure 18 demonstrates graphically the relationship

$$
\mu=-0.05 V+5.3
$$

where $V$ is in $\mathrm{m} \mathrm{s}^{-1}$, and the straight-line fit to

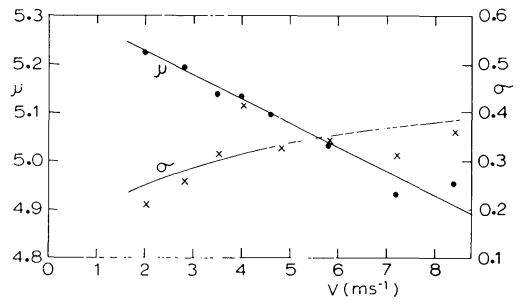

Fig. 18 Showing the variation of the lognormal parameters $\mu$ and $\sigma$ with impact velocity, $V$. These data are given in Table 3 and the corresponding lognormal distributions of ejecta are given in Figure 5.

these data shows a correlation coefficient of 0.98 . The corresponding relationship for $\sigma$ was less precise and suggests

$$
\sigma=0.3 V^{0.22}
$$

with a correlation coefficient here of 0.70 . As shown in Figure 5, the combined effect of these two relationships was most noticeable in the region of small droplet diameters $(d<100 \mu)$ where numbers increased appreciably as $V$ was increased. The accompanying increase in numbers of droplets of larger diameters implies a continuing flow of water into the crown during disruption that is greater at large impact velocities.

\section{(c) The influence of drop size}

Table 4 shows that there is a small but systematic increase in the log-normal parameter $\mu$ as the diameter of the impacting drop is increased. This is a contrary behaviour to that given in Table 3 where an increase in the kinetic energy of impact shows an accompanying decrease in $\mu$. As before, the quantity $\sigma$ increases with increasing kinetic energy of impact. Thus the combined data of Tables 3 and 4 demonstrate clearly that it is not possible to explain the splashing event solely in terms of kinetic energy, even if data such as those described by Equation (3) show a simple relationship between the total number of products and kinetic energy for a given size of impacting drop. For some applications of these results, it may be more appropriate to use the Weber number as an index.

An increase in $\mu$ with the diameter of the impacting drop is to be expected owing to the creation of a thicker wall and crown by a larger volume of liquid. The increase in $\sigma$ with drop size appears to correspond to no simple physical explanation. 
(d) The influence of surface tension forces

Table 5 and Figure 9 show that the numbers of droplets produced by a given splashing event is only weakly influenced by surface tension forces; a factor-of-two change in $\gamma$ provided only a 20 percent change in $N$. These data also show that the log-normal distribution width is essentially unaffected.

The most significant effect to be noted is best judged from Figure 9, where the curves for $\gamma=$ 0.052 and $0.035 \mathrm{~N} \mathrm{~m}^{-1}$ are seen to be identical in all respects but distinct from the curve for $\gamma=0.073 \mathrm{~N} \mathrm{~m}^{-1}$ (distilled water) by virtue of the shift of the mode from that of the latter $(130 \mu)$ to $100 \mu$. Thus, in the examples given, the reduction of $\gamma$ from 0.073 to $0.052 \mathrm{~N} \mathrm{~m}^{-1}$ (a change of $30 \%$ ) triples the number of droplets produced of diameter 75 microns; correspondingly, the numbers of droplets with diameters in excess of 200 microns is approximately halved. The shift to smaller sizes of droplets when the surface tension forces are reduced is thought to be a direct consequence of the expected associated reduction of the wavelength of capillary waves on the surface of the wall and crown.

(e) The influence of thin liquid films spread over the target surface

Table 6 shows many of the salient features associated with this aspect of the investigation. The dependence of $N$ upon the film thickness, $t$, is non-linear with few products generated at $t=$ $0.03 \mathrm{~mm}$. Numbers rise rapidly to a peak near $t=0.06 \mathrm{~mm}$ and thereafter decline in a linear fashion as $t$ increases. A similar pattern of be-

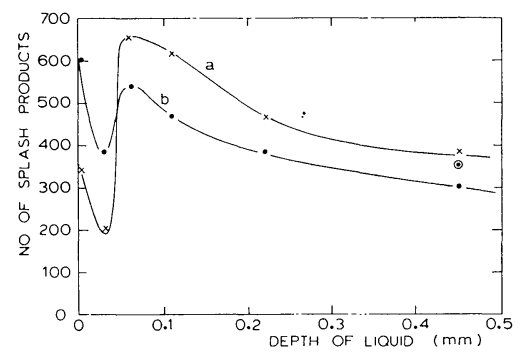

Fig. 19 The total number of splash products, $N$, resulting from impacts between a drop of radius $2 \mathrm{~mm}$ and targets of varying roughness covered by liquid liquid films of different thickness, $t$ : (a) medium-rough target; (b) rough target. These data are taken from Tables 6,7, and 8. The smooth-target data constitute an isolated point at $t=0.45 \mathrm{~mm}$. haviour is shown in Table 7 for the target with a rough surface with $N$ frequently less than the dry surface value; Figure 19 summarises these features. For values of $t$ greater than $0.06 \mathrm{~mm}$, data points were fitted to a straight-line function giving

$$
\begin{aligned}
N(\text { medium } \text { surface }) & =677-700 t \\
N(\text { rough } \text { surface }) & =539-571 t
\end{aligned}
$$

It is of interest to note that Equations (11) and (12) both predict a value $N=-72$ when $t=1.07$ $\mathrm{mm}$. Actual curve trends deviate from the straight-line relationships given and therefore such an extrapolation of the data beyond $t=$ $0.45 \mathrm{~mm}$ is doubly unwise. Nevertheless, the adoption of a rule-of-thumb value of $t=1 \mathrm{~mm}$ for the elimination of sub-surface effects is a useful criterion. (Hobbs and Osheroff (1967) noted that certain film thicknesses inhibited droplet ejection.)

From Tables 6 and 7 it may be seen that the log-normal parameter $\mu$ is much reduced when $t=0.03 \mathrm{~mm}$ but remains relatively constant when thicker layers cover the target. The parameter $\sigma$ shows a similar behaviour for small $t$ but displays clearly that it is an increasing function of $t$ at all times. Thus, over the range of $t$ studied,

$$
\begin{aligned}
\sigma(\text { medium surface }) & =0.9 t^{0.24} \\
\sigma(\text { rough surface }) & =0.7 t^{0.13}
\end{aligned}
$$

That is, as the depth of the liquid film increases, the width of the distribution broadens. As shown in Figure 11, there is an accompanying increase in the number of droplets of greater than about 200 microns diameter; changes in the numbers of small droplets are not so marked. At large values of $t$ the properties of the splashing event become more or less independent of substrate type, as is clearly demonstrated in Figure 14 where the depth $t$ is $0.45 \mathrm{~mm}$. When a water drop splashes into thin layers of liquid, water from the layer is incorporated into the wall and crown, so that the wall may be expected to thicken. As a consequence of this, larger jets will be formed which give rise to larger droplets. The liquid wall may also be expected to rise further from the target surface than for a similar impact in dry conditions so that if the liquid film on the target is very thin the wall may actually be thinner than in any other situation of dry or wet impact and small droplets will result. This effect may be clearly seen in Figure 11 for the medium surface and is present to a lesser extent for the rough surface, as shown in Figure 13; 
in the latter case, the influence of surface roughness is apparent owing to the liquid layer being rather thin.

\section{( $f$ ) The influence of curvature of the target} surface

An increase in the curvature of the target necessarily implies a reduction of its surface area. Levin and Hobbs (1971) found that a drop had a maximum diameter of spread (excepting ejecta) of about $10 \mathrm{~mm}$, thus curvatures of the order used in the experiments described here can be expected to influence the splashing process in some way.

An examination of Tables 9 and 10 shows that only small changes in $N$ occur when the radius of curvature of the target is varied, though in both situations the maximum $N$ is associated with a radius of curvature, $C$, of $0.8 \mathrm{~cm}$. The lognormal parameter, $\sigma$, also shows a maximum: at $C=0.8 \mathrm{~cm}$ for the impact with a drop of $2 \mathrm{~mm}$ radius, and at $C=0.65 \mathrm{~cm}$ for the impact with a drop of $1.1 \mathrm{~mm}$ radius. The reason for this behaviour is not clear. The parameter $\mu$, on the other hand, showed an almost linear dependence upon $C$, giving

$$
\begin{aligned}
& \mu(R=2.0 \mathrm{~mm})=5.3-0.24 C \\
& \mu(R=1.1 \mathrm{~mm})=5.4-0.27 C
\end{aligned}
$$

each straight-line relationship showing a correlation coefficient of about 0.98 with the data points. No supporting information giving details of the hydrodynamical behaviour of water drops splashing on curved surfaces could be found in the literature. In relation to other work described here, there is an implication that the wall from which the crown and jets develop thickens as $C$ decreases in magnitude; there is no obvious reason why this should happen.

\section{(g) The nature of the radial distribution of ejecta}

Reference to Figures $6,8,10,12$, and 16 shows that in virtually every case droplets of increasing size are found further away from the point of impact, with the exception of those lying in the size group of the greatest diameters $(200 \mu<d<700 \mu)$. Presumably the majority of droplets are ejected from the crown at a more or less fixed velocity characteristic of the radial rate of flow into the crown. Thus the droplets of greater momentum should be found at greater distances from the point of impact. Levin and Hobbs (1971) noted that, at the onset of the collapse of the crown, the jets thicken so that

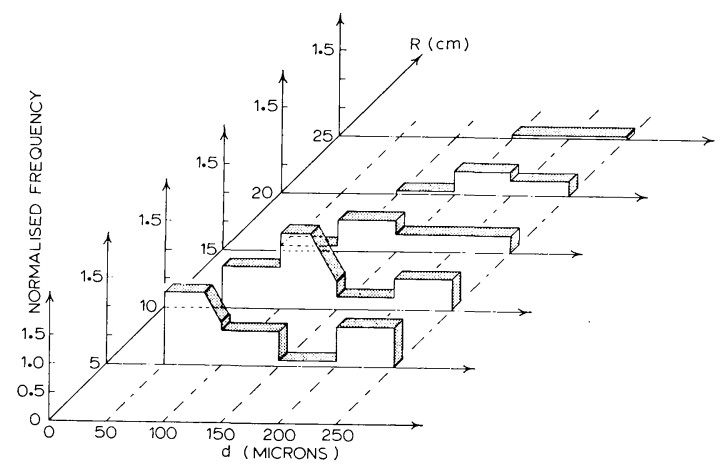

Fig. 20 A different presentation of the data of Figure 16 for the condition $C=$ $0.8 \mathrm{~cm}$, showing the variation of the size distribution of droplet products with distance, $R^{\prime}$ from the impact point.

any droplets formed will be large.

At the same time the kinetic energy due to radial flow must decrease and therefore the final droplets ejected before the collapse of the crown is complete should be located close to the impact point. The measured distributions were in qualitative agreement with these predictions; the mode for droplets of diameter less than 100 microns being generally found at a distance of less than $10 \mathrm{~cm}$ from the point of impact; and virtually no droplets less than 100 microns in diameter were located beyond a distance of $20 \mathrm{~cm}$ (though these effects can be partly attributed to the evaporation of the very smallest droplets during flight); droplets in the diameter range greater than about 200 microns have a mode that is almost always found close to the impact point. Figure 20 demonstrates these features in a reconstruction from Figure 16 of the data obtained when $C=0.8 \mathrm{~cm}$; it is clear from Figure 20 that the size distribution of ejecta at any particular distance, $R^{\prime}$ from the impact point will not permit of a fit to the log-normal distribution.

\section{Conclusions}

A study of the products caused by the splashing of a water drop onto a prepared surface has been made which has demonstrated that the numbers and sizes of the products are quantities which may be predicted with a better than orderof-magnitude accuracy if the initial conditions are known. Exhaustive tests have demonstrated that the overall size distribution may be modelled by a log-normal function with confidence and confirm the findings based on rather less evidence 


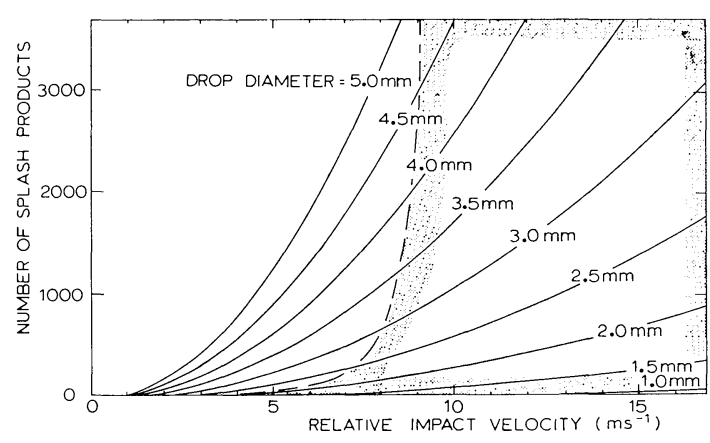

Fig. 21 The total number of droplets, $N$, predicted by Equation (8) to be produced when drops of different sizes impact with a medium-rough target at various values of impact velocity, $V$. The dashed curve shows the terminal velocity of fall in still air; the hatched area requires impacts at a velocity greater than the terminal velocity.

by Levin (1970) and Levin and Hobbs (1971); the function is shown not to be a useful model for other marginal distributions of droplet size. In many circumstances it has proved possible to quantify changes of the log-normal parameters in terms of controlling influences such as target radius of curvature, the thickness of liquid covering the target surface, and velocity of impact. For example, Equation (8) may be used to establish the total number of droplets, $N$, that will be produced when water drops of a given size collide with a surface of medium roughness at a particular impact velocity: Levin and Hobbs show data for the products of the impact of a drop of radius $1.25 \mathrm{~mm}$ at $4.8 \mathrm{~m} \mathrm{~s}^{-1}$ with a medium rough copper hemisphere of radius $1.2 \mathrm{~cm}$. For this situation they quote $N=110$, and $\mu$ is approximately 5.11 (165 microns); calculations based on the equations given here provide $N=90$ and $\mu=5.05$ (156 microns) in reasonable agreement with experiment. Figure 21 shows the results of such calculations. The dashed line shows the terminal velocity of fall in stagnant air (Gunn and Kinzer, 1949), from which it may be deduced that drops of diameter less than about $1.5 \mathrm{~mm}$ require a relative velocity of impact which is greater than their terminal velocity; such an effect was noted by Hobbs and Alkezweeny (1967). The applications of these and other data derived from the experiments described here to problems of interactions between precipitation particles in mature cloud systems are obvious. Calculations based on such problems are in progress. In addition, further experimental work to exactly correlate the hydrodynamics of the splashing event to the nature of the ejecta is urgently required in order to explain the behaviour patterns described in this article.

\section{References}

Aitchinson, J., and J.A. C. Brown, 1957: The lognormal distribution. Cambridge University Press.

Bikerman, J. J., 1970: Physical surfaces. Academic Press.

Engel, O. G., 1955: Waterdrop collisions with solid surfaces. J. Res. Nat. Bur. Stds., 54, 281-298.

, 1966: Crater depth in fluid impacts. $J$. Appl. Phys., 37, 1798-1808.

, 1967: Initial pressure, initial flow velocity and the time dependence of crater depth in fluid impacts. J. Appl. Phys., 38, 3935-3940.

Gregory, P. H., E. J. Guthrie, and M.E. Bunce, 1959: Experiments on splash dispersal of fungus spores. J. Gen. Microbiol., 20, 328-354.

Gunn, R., and G.D. Kinzer, 1949: The terminal velocity of fall for water droplets in stagnant air. J. Met., 6, 243-248.

Hobbs, P. V., and A. J. Alkezweeny, 1967: Splashing of a water drop. Science, 155, 1112-1114.

, and T. Osheroff, 1967: Splashing of drops on shallow liquids. Science, 158, 1184-1186.

Koenig, L. R., and P. A. Spyers-Duran, 1961: Simple method of determining water drop sizes by means of photographic emulsions. Rev. Sci. Instrum., 32, 909-913.

Levin, Z., 1970: "Splashing of water drops: A study of the hydrodynamics and charge separation." Ph.D. thesis. Univ. of Washington, Seattle, U.S.A.

, and P. V. Hobbs, 1971: Splashing of water drops on solid and wetted surfaces: hydrodynamics and charge separation. Phil. Trans.

...Roy. Soc. Lond. A, 269, 555-585.

Macklin,.W. C., and P. V. Hobbs, 1969: Subsurface phenomena and the splashing of drops on shallow liquid. Science, 166, 107-108.

Stainer, R. D., and C.D. Stow., 1976: A study of direct methods for the measurement of small water drops. N.Z. J. Sci., 19, 135-143.

Worthington, A. M., 1876: On the forms assumed by drops of liquids falling vertically on a horizontal plate. Proc. Roy. Soc. Lond., 25, 261271.

Green and Co. 


\title{
水滴のスプラッシュによる物理的現象
}

\author{
C. D. Stow • R. D. Stainer* \\ オークランド大学物理学科大気物理学研究室 \\ ニュージーランド
}

水滴のスプラッシュにともなら種々の物理的な現象が, 衝突速度, 水滴半径, 表面張力, 衝突面の曲率半径や粗 さ, さらに衝突面上の水膜の厚さといったパラメーターのもとに研究された。その結果, ネプラッシュによってでき る微水滴の数は, 衝突面の粗さ, 衝突速度, 水滴の大きさとともに增すが, 水膜の厚さが増加したり, また水滴の表 面張力の減少とともに減ることがわかった。ある大きさの水滴に対して，スプラッシュが生成される数は衝突時の運 動エネルギーに比例していた。スプラッシュによる微水滴の粒径分布はほぼ log-nomal の形で, とび出る微水滴の 平均粒径は使用する水滴, 衝突面の粗さ, 水膜の厚さとともに增えるが, 衝突速度の増加や表面張力の減少とともに 減った。

スプラッシュによって生成される微水滴の数 $(\mathrm{N})$ は水平な面に衝突させる水滴の半径 $(\mathrm{r} \mathrm{cm})$ とその速度 $(\mathrm{V}$ $\left.\mathrm{m} \cdot \mathrm{s}^{-1}\right)$ によって表わされ，その関係式は $\left(\mathrm{N}=3400 \mathrm{r}^{3} \mathrm{~V}^{2}-63\right.$ である。また半径 $0.75 \mathrm{~mm}$ より小さな水滴を用いて 微水滴をとび出させるには水滴の終末速度より大きな衝突速度が必要であることもわかった。

* 現在所属 : ニュージランド気象局, ウェリントン, ニュージーランド 